\title{
One hundred years of Molecular Genetics and Genomics: 100 years of extra-nuclear inheritance
}

\author{
Stefan Hohmann • Rudolf Hagemann
}

Published online: 4 February 2010

(C) Springer-Verlag 2010

The journal Molecular Genetics and Genomics (MGG) was founded in 1908, 102 years ago, under the name "Zeitschrift für induktive Abstammungs-und Vererbungslehre". It was the first journal worldwide dedicated to genetics.

The rediscovery of the Mendelian laws of inheritance in 1900 provided an intense impetus for hereditary studies on plants and animals. Many different organisms were used for investigation. Very soon an urgent need was felt by many investigators for a scientific journal publishing studies on heredity and genetic variation. The first researcher who took the initiative to found such a journal was Dr. Erwin Baur, at that time a scientific assistant at the Botanical Institute of the University of Berlin. But Baur was rather young at that time, just 33 years of age. Therefore, it seemed wise to involve established professors of biology as editors of such a journal. Baur was successful in recruiting as editors Carl Correns (botanist, Leipzig, later Münster), Valentin Haecker (zoologist, Stuttgart, later Halle), Richard von Wettstein (botanist, Vienna) and Gustav Steinmann (palaeontologist, Bonn). The initiator, Erwin Baur, accepted the position of 'Managing Editor' ('geschäftsführender Redakteur'). He served in that role from 1908 until his untimely death in 1933.

In summer 1908, the first issue of the new journal, "Zeitschrift für induktive Abstammungs-und Vererbungslehre", was published. This rather long name was

S. Hohmann $(\bowtie) \cdot$ R. Hagemann Department for Cell and Molecular Biology,

University of Gothenburg, Box 462,

Göteborg 40530, Sweden

e-mail: editor@molecular-genetics-genomics.se chosen to emphasise the journal's focus on studies on heredity, variation and evolution. Work published in the journal should concentrate on experimental studies (i.e. 'inductive'). Purely theoretical speculations on heredity and evolution were intended to be excluded from publication. At that time, the term "genetics" proposed by W. Bateson in 1906 had not yet found its way into German scientific language. In Germany, the journal was usually abbreviated ZfiAuVererbungsl. or just ZfiAuV. In other European countries, it was mostly called Baur's Journal.

ZfiAuV was worldwide the first journal entirely devoted to genetics. In the following years (between 1909 and 1920), genetics journals were founded in other countries as well, beginning with the Journal of Heredity (USA) in 1909 and followed by the Journal of Genetics (England), Genetics (USA), Genetica (The Netherlands) and Hereditas (Sweden).

In contrast to those other journals, ZfiAuV changed names since in order to reflect the development of the field as well as the move towards English as sole scientific publication language. The initial name "Zeitschrift für induktive Abstammungs-und Vererbungslehre" was used until 1958. In 1958 (Vol. 89), the name was changed to the somewhat shorter "Zeitschrift für Vererbungslehre". In 1967 (Vol. 99), the name was internationalised and modernised into "Molecular and General GeneticsMGG", which was changed again in 2001 (Vol. 265) to "Molecular Genetics and Genomics", keeping the abbreviation MGG.

MGG is the direct continuation of "Baur's Journal" founded in 1908 and now Vol. 283 is in publication. The members of the Editorial Board of MGG are proud to work for the world' first journal of genetics.

Interestingly, the first Volume of MGG (ZfiAuV) also laid the foundation for a new field in genetics: non-Mendelian 
or extranuclear genetics. In Vol. 1, issue 3, published in spring 1909, Erwin Baur and Carl Correns published, back to back, two papers on non-Mendelian inheritance of chlorophyll deficiencies in higher plants. On the 100th anniversary of the publication of these seminal papers, MGG publishes a historical review on the foundation of extra-nuclear inheritance.

Gothenburg and Halle, January 2010

Stefan Hohmann and Rudolf Hagemann 